\title{
Function of FXYD Proteins, Regulators of Na,K-ATPase
}

\author{
Käthi Geering ${ }^{1}$
}

\begin{abstract}
In this short review, we summarize our work on the role of members of the FXYD protein family as tissue-specific modulators of Na,K-ATPase. FXYD1 or phospholemman, mainly expressed in heart and skeletal muscle increases the apparent affinity for intracellular $\mathrm{Na}^{+}$of $\mathrm{Na}, \mathrm{K}-$ ATPase and may thus be important for appropriate muscle contractility. FXYD2 or $\gamma$ subunit and FXYD4 or CHIF modulate the apparent affinity for $\mathrm{Na}^{+}$of $\mathrm{Na}, \mathrm{K}-\mathrm{ATPa}$ e in an opposite way, adapted to the physiological needs of $\mathrm{Na}^{+}$reabsorption in different segments of the renal tubule. FXYD3 expressed in stomach, colon, and numerous tumors also modulates the transport properties of Na,K-ATPase but it has a lower specificity of association than other FXYD proteins and an unusual membrane topology. Finally, FXYD7 is exclusively expressed in the brain and decreases the apparent affinity for extracellular $\mathrm{K}^{+}$, which may be essential for proper neuronal excitability.
\end{abstract}

KEY WORDS: FXYD proteins; $\mathrm{Na}, \mathrm{K}-\mathrm{ATPase}$ regulation; $\mathrm{Na}^{+}$reabsorption; muscle contractility; neuronal excitability.

\section{INTRODUCTION}

The ubiquitous $\mathrm{Na}, \mathrm{K}$-ATPase transports $3 \mathrm{Na}^{+}$out of the cell in exchange for $2 \mathrm{~K}^{+}$by using the energy of the hydrolysis of one ATP. The main task of Na,K-ATPase is to maintain the $\mathrm{Na}^{+}$and $\mathrm{K}^{+}$gradients between the intra- and extracellular milieu of animal cells, which are essential for basic cellular homeostasis. Moreover, Na,K-ATPase is essentially involved in specialized tissue functions such as renal $\mathrm{Na}^{+}$reabsorption, muscle contraction, and neuronal excitability.

$\mathrm{Na}, \mathrm{K}$-ATPase is an oligomeric protein. The catalytic $\alpha$ subunit, which has 10 transmembrane domains, hydrolyses ATP and transports the cations whereas the $\beta$ subunit acts as a molecular chaperone necessary for the correct membrane insertion of the $\alpha$ subunit (Geering, 2001). Four $\alpha$ and $3 \beta$ isoforms exist which show tissue-specific distribution and which can potentially form 12 different

\footnotetext{
${ }^{1}$ Department of Pharmacology and Toxicology, University of Lausanne, Rue du Bugnon 27, CH-1005 Lausanne, Switzerland; e-mail: kaethi. geering@unil.ch.
}

$\mathrm{Na}, \mathrm{K}$-ATPase isozymes with different transport properties (Crambert et al., 2000).

In view of its important physiological role, $\mathrm{Na}, \mathrm{K}$ ATPase expression and/or activity must be finely regulated. The intracellular $\mathrm{Na}^{+}$concentration is the rate limiting factor for the activity of Na,K-ATPase and thus any change in the intracellular $\mathrm{Na}^{+}$concentration will affect the transport rate of Na,K-ATPase. Moreover, hormones and neurotransmittors determine the number of functional $\mathrm{Na}, \mathrm{K}$-ATPase units at the cell surface either by modulating the distribution of Na,K-pumps between the plasma membrane and intracellular stores, or by controlling gene transcription (Feraille and Doucet, 2001). Recently, a novel regulatory mechanism has been elucidated which involves tissue- and isozyme-specific interaction of Na,K-ATPase with small membrane proteins of the FXYD protein family (Crambert and Geering, 2003).

In mammals, the FXYD protein family contains seven members (Sweadner and Rael, 2000) including FXYD1 (or phospholemman) (Palmer et al., 1991), FXYD2 (or the $\gamma$ subunit of Na,K-ATPase) (Forbush et al., 1978; Mercer et al., 1993), FXYD3 (or mammary tumor marker Mat-8) (Morrison et al., 


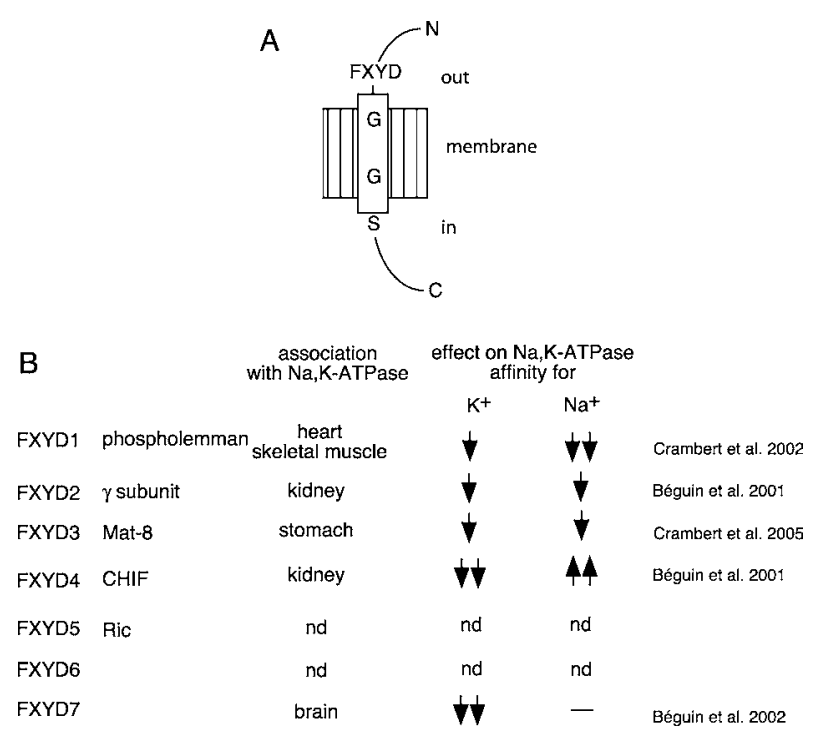

Fig. 1. The FXYD protein family. (A) Membrane topology of FXYD proteins with indications of the positions of conserved amono acid residues. (B) The seven members of the FXYD protein family. Indicated are the tissues in which FXYD proteins could be coimmunoprecipitated with Na,K-ATPase and the functional effect of FXYD proteins on $\mathrm{Na}, \mathrm{K}$-ATPase affinity for $\mathrm{K}^{+}$and $\mathrm{Na}^{+}$as measured after coexpression in Xenopus oocytes. For details see text.

1995), FXYD4 (or corticosteroid hormone-induced factor CHIF) (Attali et al., 1995), FXYD5 (or related to ion channel RIC or dysadherin) (Fu and Kamps, 1997), FXYD6 (or phosphohippolin) (Yamaguchi et al., 2001), and FXYD7 (Béguin et al., 2002). Moreover, FXYD2 from Xenopus laevis (Béguin et al., 1997) and a phospholemman-like protein from shark (Mahmmoud et al., 2003) have been cloned. These proteins are characterized by a FXYD motif, two conserved glycine residues, and a serine residue. Most FXYD proteins, which have been studied so far, are type I membrane proteins exposing their $\mathrm{N}$-terminus to the extracytoplasmic side (Béguin et al., 1997, 2001, 2002; Palmer et al., 1991) (Fig. 1(A)). FXYD1 (Palmer et al., 1991) and FXYD4 (Béguin et al., 2001) adopt this membrane orientation after cleavage of a signal peptide. Several posttranslational modifications have been identified, e.g., kinase-mediated phosphorylation in FXYD1 or phospholemman (Palmer et al., 1991) or O-glycosylation in FXYD7 (Béguin et al., 2002). Finally, it is interesting to note that a mutation of a conserved glycine residue into an arginine residue in FXYD2 or the $\gamma$ subunit has been linked to cases of human hypomagnesemia (Meij et al., 2000).

FXYD2 or the $\gamma$ subunit was the first FXYD protein that was shown to be associated with renal Na,K-ATPase
(Forbush et al., 1978), and to modulate its transport properties (Béguin et al., 1997). During the last few years, we and others have identified five out of seven FXYD proteins as specific modulators of Na,K-ATPase. All affect the apparent affinity for extracellular $\mathrm{K}^{+}$of $\mathrm{Na}, \mathrm{K}$-ATPase (Béguin et al., 2001, 2002; Crambert et al., 2002, 2005). In addition, FXYD1 (Crambert et al., 2002), FXYD2 (Arystarkhova et al., 1999; Béguin et al., 2001; Pu et al., 2001), FXYD3 (Crambert et al., 2005), and FXYD4 (Béguin et al., 2001; Garty et al., 2002) affect the apparent affinity for internal $\mathrm{Na}^{+}$of $\mathrm{Na}, \mathrm{K}$-ATPase in a way which is consistent with the physiological demands of the tissues in which they are expressed.

In the following, I will summarize our recent published work on the characterization of FXYD proteins, their effects on the $\mathrm{Na}, \mathrm{K}$-ATPase, and the identification of interaction sites between FXYD proteins and $\mathrm{Na}, \mathrm{K}-$ ATPase (Figs. 1 and 2).

\section{FXYD1 (PHOSPHOLEMMAN)}

FXYD1 is widely distributed with highest expression in heart and skeletal muscle (Chen et al., 1997). FXYD1 produces chloride-activated currents (Moorman et al., 1995) and transports the zwitterionic amino acid taurine (Kowdley et al., 1997) after expression in Xenopus oocytes or added to lipid bilayers. Moreover, it was recently shown that FXYD1 colocalizes with $\mathrm{Na} / \mathrm{Ca}$ exchanger and coimmunopreciptation experiments suggest a direct interaction between the two proteins (Mirza et al., 2004), which leads to inhibition of the $\mathrm{Na} / \mathrm{Ca}$ exchanger (Zhang et al., 2003).

We have recently shown that FXYD1 associates stably with six different Na,K-ATPase isozymes after coexpression in Xenopus oocytes, and with $\alpha 1-\beta$ and to a lesser extent with $\alpha 2-\beta$ complexes in heart and skeletal muscles (Crambert et al., 2002). In Xenopus oocytes, stoichiometric association of FXYD1 and $\mathrm{Na}, \mathrm{K}$-ATPase occurs posttranslationally. As assessed by voltage-clamp techniques, association of FXYD1 with Na,K-ATPase produces a small increase in the apparent affinity of $\mathrm{Na}, \mathrm{K}$-ATPase for external $\mathrm{K}^{+}$and an about twofold increase in the affinity for internal $\mathrm{Na}^{+}$(Crambert et al., 2002) (Fig. 1(B)). This increase in the internal $\mathrm{Na}^{+}$affinity of $\mathrm{Na}, \mathrm{K}$-ATPase may be favorable in excitable tissues such as heart and skeletal muscle to extrude efficiently increased intracellular $\mathrm{Na}^{+}$ during action potentials and to ensure appropriate muscle contractility.

The question remains to be answered what mechanisms regulate the potentially multiple functions of 
FXYD1, e.g., whether phosphorylation or hormonal stimulation influence the role of FXYD1 as a channel-forming protein, as a modulator of $\mathrm{Na} / \mathrm{Ca}$ exchanger, or as a regulator of $\mathrm{Na}, \mathrm{K}-\mathrm{ATPase}$.

\section{FXYD2 $(\gamma$ SUBUNIT) AND FXYD4 (CHIF)}

The two spliced variants FXYD2a and FXYD2b are mainly expressed in the medullary thick ascending limb of the kidney (Kuster et al., 2000; Pu et al., 2001; Sweadner and Rael, 2000) and FXYD4 is abundant in the distal colon and the medullary collecting duct of the kidney (Shi et al., 2001).

Our studies show that FXYD2 variants (Béguin et al., 1997, 2001) and FXYD4 (Béguin et al., 2001) associate with $\mathrm{Na}, \mathrm{K}$-ATPase $\alpha 1-\beta$ complexes both after coexpression in oocytes and in the kidney. Association of FXYD2 is not necessary for the expression and activity of $\mathrm{Na}, \mathrm{K}$ ATPase but the stability of FXYD2 itself depends on the association with Na,K-ATPase (Béguin et al., 1997). The FXYD motif of FXYD2 and FXYD4 is necessary for the stable association with $\mathrm{Na}, \mathrm{K}-\mathrm{ATP}$ ase (Béguin et al., 2001).

Interaction of FXYD2a and FXYD2b affects slightly the apparent affinity for extracellular $\mathrm{K}^{+}$and $\mathrm{Na}^{+}$and decreases the apparent affnity for intracellular $\mathrm{Na}^{+}$of $\mathrm{Na}, \mathrm{K}-$ ATPase. On the other hand, interaction with FXYD4 affects the apparent affinity for extracellular $\mathrm{K}^{+}$and $\mathrm{Na}^{+}$ and increases twofold the apparent affinity for intracellular $\mathrm{Na}^{+}$(Béguin et al., 2001) (Fig. 1(B)). Positively charged residues in the cytoplasmic domain are important for the functional effects of FXYD4. The differential effects of FXYD2 and FXYD4 on the affinity for intracellular $\mathrm{Na}^{+}$of Na,K-ATPase are likely to be of physiological relevance and may reflect the different roles of $\mathrm{Na}, \mathrm{K}$-ATPase in the $\mathrm{Na}^{+}$reabsorption process in different segments of the renal nephron. FXYD2 is mainly expressed in the thick ascending limb, which reabsorbs up to $40 \%$ of the filtered $\mathrm{Na}^{+}$load. In this renal segment, a decrease in the $\mathrm{Na}^{+}$affinity of Na,K-ATPase by association with FXYD2 is favorable and permits efficient extrusion of cellular $\mathrm{Na}^{+}$even at high intracellular $\mathrm{Na}^{+}$concentrations. In contrast, FXYD4 is exclusively expressed in the collecting duct which is the ultimte site of electrolyte conservation. In this renal segment, an increase in the $\mathrm{Na}^{+}$affinity of $\mathrm{Na}, \mathrm{K}$-ATPase by the association with FXYD4 is favorable and permits efficient $\mathrm{Na}^{+}$reabsorption even at low intracellular $\mathrm{Na}^{+}$concentrations. From the effect of FXYD4 on the $\mathrm{Na}^{+}$affinity, it can be estimated that at low physiological intracellular $\mathrm{Na}^{+}$con- centrations, Na,K-ATPase associated with FXYD4 has an about fourfold higher transport rate than Na,K-ATPase lacking FXYD4.

\section{FXYD3 (Mat-8)}

Most recently, we have studied a fifth member of the FXYD family namely FXYD3. FXYD3 or Mat-8, mammary tumour marker was previously identified as a phospholemman-like protein inducing a chloride conductance when overexpressed in Xenopus laevis oocytes (Morrison et al., 1995). FXYD3 is expressed at high levels in uterus, stomach, and colon (Morrison et al., 1995). Significantly, FXYD3 is overexpressed in human breast cancer tumors and in tumors initiated by c-neu or v-Haras oncongenes but not in tumors initiated by the c-myc oncogene (Morrison and Leder, 1994). Moreover, FYXD3 has been implicated in both antiproliferating (Maxwell et al., 2003) and proliferating processes (Grzmil et al., 2004).

Our studies revealed un uncommon membrane topology of FXYD3. The SignalP program predicts a signal peptide cleavage site with high probabitity in FXYD3 similar to FXYD4. To monitor the signal petide cleavage, we expressed FXYD3 in a reticulocyte lysate in the absence or presence of dog pancreatic microsomes. Surprisingly, both in the absence and presence of microsomes, the wildtype FXYD3 migrated at a higher molecular mass than a truncated mutant lacking $22 \mathrm{~N}$-terminal amino acids. Moreover, FXYD3 expressed in oocytes, in transfected HEK cells or in the stomach has a similar molecular mass than that of FXYD3 expressed in vitro. These results suggest that the signal peptide of FXYD3 is not cleaved and that in contrast to all other FXYD proteins studied, which adopt a type I orientation, FXYD3 most likely has two transmembrane segments (Crambert et al., 2005).

Similar to other FXYD proteins, FXYD3 associates with Na,K-ATPase after expression in Xenopus oocytes and does not associate with sarcoplasmic, endoplasmic reticulum Ca-ATPase. However, in contrast to other FXYD proteins, FXYD3 also associates with gastric and colonic $\mathrm{H}, \mathrm{K}$-ATPase and thus has a lower specificity. Moreover, the processing of the $\beta$ subunit of Na,K-ATPase and H,K-ATPase from a coreglycosylated to a fully glycosylated form is significantly delayed by FXYD3 suggesting that FXYD3 may interfere with the ER exit of these proteins or with the sorting pathway to the plasma membrane (Crambert et al., 2005).

In view of the lower interaction specificity of FXYD3 with Na,K-ATPase observed in Xenopus oocytes, we 
looked whether in the stomach, where both Na,K-ATPase and H,K-ATPase are expressed, FXYD3 is associated with both ATPases. In stomach microsomes, FXYD3 can only be coimmunoprecipitated with a Na,K-ATPase $\alpha$ subunit antibody and not with a H,K-ATPase $\alpha$ subunit antibody (Fig. 1(B)). To better understand the reason for this specificity, we investigated the localization of FXYD3 in the gastric gland. FXYD3 is mainly expressed in cells forming the upper part of the gastric gland namely in the mucus cells and is absent in H,K-ATPase-containing cells, namely the parietal cells. On the other hand, FXYD3 colocalizes with $\mathrm{Na}, \mathrm{K}$-ATPase in the mucus cells at the basolateral membrane. Thus, the specificity of interaction of FXYD3 with Na,K-ATPase in situ is due to the fact that FXYD3 is not expressed in H,K-ATPase containing cells. Finally, FXYD3 is also expressed in the apical membrane of mucus cells suggesting that it may have other functions in addition to its regulation of $\mathrm{Na}, \mathrm{K}$-ATPase (Crambert et al., 2005).

Studies on the effect of FXYD3 on the Na,K-ATPase transport properties after coexpression in Xenopus oocytes revealed that FXYD3 increases the $K_{1 / 2}$ value for extracellular $\mathrm{K}^{+}$over a large range of membrane potentials and also the $K_{1 / 2}$ value for intracellular $\mathrm{Na}^{+}$(Crambert et al., 2005) (Fig. 1(B)).

In conclusion, our results show that FXYD3 is able to associate with $\mathrm{Na}, \mathrm{K}$-ATPase to modify its transport properties similar to other FXYD proteins. However, in addition to this shared function, FXYD3 shows some uncommon characteristics, e.g., its untypical membrane topology, its lower specificity, and its effect on the glycosylation processing. The physiological relevance of these characteristics remains to be determined. Further experiments are also needed to show whether regulation of the functional properties of Na,K-ATPase by FXYD3 leading to a modification of the ionic cellular milieu may be important for triggering or impeding cell proliferation.

\section{FXYD7}

FXYD7 is exclusively expressed in brain both in neurons and glial cells (Béguin et al., 2002). Expressed in Xenopus oocytes, FXYD7 associates with $\alpha-\beta 1$ but not with $\alpha-\beta 2 \mathrm{Na}, \mathrm{K}$-ATPase isozymes whereas in the brain, FXYD7 can only be coimmunoprecipited with $\alpha 1$ antibodies (Béguin et al., 2002) (Fig. 1(B)). FXYD7 contains a $\mathrm{C}$-terminal valine residue, which is involved in a rapid ER export and may explain the observed posttranslational association of FXYD7 with Na,K-ATPase (Crambert et al., 2004).
FXYD7 decreases the apparent affinity for external $\mathrm{K}^{+}$over a large range of membrane potentials in the absence and presence of external $\mathrm{Na}^{+}$. Moreover, the activity of Na,K-ATPase associated with FXYD7 is more strongly inhibited by external $\mathrm{Na}^{+}$than that of the $\mathrm{Na}, \mathrm{K}$-ATPase lacking FXYD7 indicating that the translocation and the release of $\mathrm{Na}^{+}$are also affected by FXYD7. These effects of FXYD7 are only observed for $\alpha 1-\beta 1$ and $\alpha 2-\beta 1$ complexes but not for $\alpha 3-\beta 1$ complexes (Béguin et al., 2002). The two conserved glycine residues, which are on the same side of the transmembrane helix of FXYD7, are involved in both the association and the functional effect of FXYD7 (Crambert et al., 2004). Finally, in contrast to the apparent $\mathrm{K}^{+}$affinity, FXYD7 does not produce an effect on the affinity for intracellular $\mathrm{Na}^{+}$(Béguin et al., 2002) (Fig. 1(B)). Na,K-ATPase determines the rate of recovery of baseline external $\mathrm{K}^{+}$during neuronal activity and is responsible for the postactivity extracellular $\mathrm{K}^{+}$ undershoot. A Na,K-ATPase/FXYF7 complex with a low affinity for $\mathrm{K}^{+}$may be of physiological relevance in the brain to ensure proper excitability of neurons and/or to prevent an excessive $\mathrm{K}^{+}$undershoot.

\section{INTERACTION SITES BETWEEN Na,K-ATPase AND FXYD PROTEINS IN THE TRANSMEMBRANE DOMAIN}

We based our analysis on the interaction sites between FXYD proteins and $\mathrm{Na}, \mathrm{K}$-ATPase on a model of the structure of renal Na,K-ATPase (Hebert et al., 2001). In this model, FXYD2 is supposed to be located in a pocket made up of transmembrane domains TM9, 6, 4, and 2 of the Na,K-ATPase $\alpha$ subunit (Fig. 2(A)). Our analysis revealed that one face of the TM9 helix plays a role in the structural and functional interaction with FXYD proteins (Li et al., 2004). Interestingly, we can distiguish different domains of interaction. Leu ${ }^{964}$ and $\mathrm{Phe}^{967}$ contribute to the stable interaction between the $\alpha$ subunit and FXYD2, FXYD4, and FXYD7 but not to the functional effect of these FXYD proteins on the apparent $\mathrm{K}^{+}$-affinity of Na,K-ATPase. On the other hand, Phe ${ }^{956}$ and Glu ${ }^{960}$ do not contribute to the stable interaction between the two proteins but transmit the $\mathrm{K}^{+}$effect of FXYD proteins to Na,K-ATPase (Fig. 2(B)). In contrast to the $\mathrm{K}^{+}$effect, the $\mathrm{Na}^{+}$effect of certain FXYD proteins such as FXYD4 is not mediated by $\mathrm{Phe}^{956}$ and Glu ${ }^{960}$. Significantly, a docking model of the Na,K-ATPase/FXYD7 complex is in very good agreement with the experimental data $(\mathrm{Li}$ et al., 2004). All residues in TM9 identified in mutagenesis studies are involved in contacts with FXYD7. In addition, the model predicts amino acids in TM2 as contact 


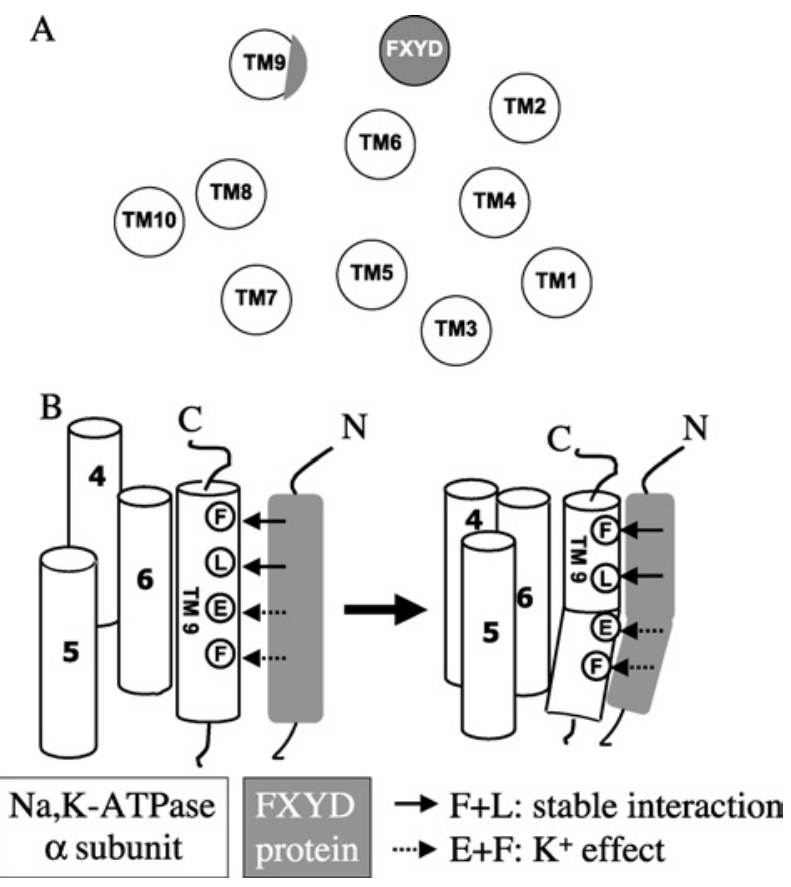

Fig. 2. Structural and functional interaction sites between $\mathrm{Na}, \mathrm{K}-\mathrm{ATPa} e$ and FXYD proteins. (A) Model of the disposition of the transmembrane (TM) helices of the $\alpha$ subunit of Na,K-ATPase in a view from the cytoplasmic side according to Hebert et al. (2001). Indicated is the putative localization of FXYD proteins and the region in TM9 of the $\alpha$ subunit which has been studied for its role in the interaction with FXYD proteins. (B). Schematic representation of the interaction site in TM9 of the $\alpha$ subunit with FXYD proteins. Indicated are amino acids which are either involved in the stable interaction with FXYD proteins or transmit the functional effect of FXYD proteins on the $\mathrm{K}^{+}$affinity of Na,K-ATPase. For details see text.

sites with FXYD7. Thus, TM9 of the Na,K-ATPase $\alpha$ subunit contributes to the structural and functional interaction with FXYD proteins, but other TM helices of the binding pocket between TM9, 6, 4, and 2 or extramembraneous interaction sites may also be involved and remain to be determined.

\section{CONCLUSIONS}

Our data indicate that all FXYD proteins are tissuespecific auxilary subunits of $\mathrm{Na}, \mathrm{K}$-ATPase which regulate its activity in agreement with the physiological requirements of the tissue in which they are expressed. On the other hand, much has still to be learnt on the mechanisms that link Na,K-ATPase modulation by FXYD proteins to physiological and pathophysiological changes of cellular homeostasis, and to reveal the existence and the significance of other possible functions of FXYD proteins, e.g., as channels or regulators of other proteins than $\mathrm{Na}, \mathrm{K}$ ATPase.

\section{ACKNOWLEDGMENT}

This work was supported by grant Nos. 31-64793.01 and $3100 \mathrm{AO}-107513$ to KG from the Swiss National Science Foundation.

\section{REFERENCES}

Arystarkhova, E., Wetzel, R. K., Asinovski, N. K., and Sweadner, K. J. (1999). J. Biol. Chem. 274, 33183-33185.

Attali, B., Latter, H., Rachamim, N., and Garty, H. (1995). Proc. Natl. Acad. Sci. U.S.A. 92, 6092-6096.

Béguin, P., Crambert, G., Guennoun, S., Garty, H., Horisberger, J.-D., and Geering, K. (2001). EMBO J. 20, 3993-4002.

Béguin, P., Crambert, G., Monnet-Tschudi, F., Uldry, M., Horisberger, J.-D., Garty, H., and Geering, K. (2002). EMBO J. 21, 3264-3273.

Béguin, P., Wang, X. Y., Firsov, D., Puoti, A., Claeys, D., Horisberger, J. D., and Geering, K. (1997). EMBO J. 16, 4250-4260.

Chen, L.-S.K., Lo, C. F., Numann, R., and Cuddy, M. (1997). Genomics 41, 435-443.

Crambert, G., Fuzesi, M., Garty, H., Karlish, S., and Geering, K. (2002). Proc. Natl. Acad. Sci. U.S.A. 99, 11476-11481.

Crambert, G., and Geering, K. (2003). Sci. STKE 166, RE1.

Crambert, G., Hasler, U., Beggah, A. T., Yu, C., Modyanov, N. N., Horisberger, J. D., Lelievre, L., and Geering, K. (2000). J. Biol. Chem. 275, 1976-1986.

Crambert, G., Li, C., Claeys, D., and Geering, K. (2005). Mol. Biol. Cell 16, 2363-2371.

Crambert, G., Li, C., Swee, L. K., and Geering, K. (2004). J. Biol. Chem. 279, 30888-30895.

Feraille, E., and Doucet, A. (2001). Physiol. Rev. 81, 345-418.

Forbush, B. III, Kaplan, J. H., and Hoffman, J. F. (1978). Biochemistry 17, 3667-3676.

Fu, X., and Kamps, M. (1997). Mol. Cell. Biol. 17, 1503-1512.

Garty, H., Lindzen, M., Scanzano, R., Aizman, R., Fuzesi, M., Goldshleger, R., Farman, N., Blostein, R., and Karlish, S. J. D. (2002). Am. J. Physiol. 283, F607-F615.

Geering, K. (2001). J. Bioenerg. Biomembr. 33, 425-438.

Grzmil, M., Voigt, S., Thelen, P., Hemmerlein, B., Helmke, K., and Burfeind, P. (2004). Int. J. Oncol. 24, 97-105.

Hebert, H., Purhonen, P., Vorum, H., Thomsen, K., and Maunsbach, A. B. (2001). J. Mol. Biol. 314, 479-494.

Kowdley, G. C., Ackerman, S. J., Chen, Z. H., Szabo, G., Jones, L. R., and Moorman, J. R. (1997). Biophys. J. 72, 141-145.

Kuster, B., Shainskaya, A., Pu, H. X., Goldshleger, R., Blostein, R., Mann, M., and Karlish, S. J. (2000). J. Biol. Chem. 275, 1844118446.

Li, C., Grosdidier, A., Crambert, G., Horisberger, J.-D., Michielin, O., and Geering, K. (2004). J. Biol. Chem. 279, 38895-38902.

Mahmmoud, Y. A., Cramb, G., Maunsbach, A. B., Cutler, C. P., Meischke, L., and Cornelius, F. (2003). J. Biol. Chem. 278, 3742737438.

Maxwell, P. J., Longley, D. B., Latif, T., Boyer, J., Allen, W., Lynch, M., McDermott, U., Harkin, D. P., Allegra, C. J., and Johnston, P. G. (2003). Cancer Res. 63, 4602-4606.

Meij, I. C., Koenderink, J. B., van Bokhoven, H., Assink, K. F., Groenestege, W. T., de Pont, J. J., Bindels, R. J., Monnens, L. A., van den Heuvel, L. P., and Knoers, N. V. (2000). Nat. Genet. 26, 265-266.

Mercer, R. W., Biemesderfer, D., Bliss, D. P., Collins, J. H., and Forbush, B. (1993). J. Cell Biol. 121, 579-586. 
Mirza, M. A., Zhang, X.-Q., Ahlers, B. A., Qureshi, A., Carl, L. L., Song, J., Tucker, A. L., Mounsey, J. P., Moorman, J. R., Rothblum, L. I., Zhang, T. S., and Cheung, J. Y. (2004). Am. J. Physiol. 286, H1322-H1330.

Moorman, J. R., Ackerman, S. J., Kowdley, G. C., Griffin, M. P., Mounsey, J. P., Chen, Z. H., Cala, S. E., Obrian, J. J., Szabo, G., and Jones, L. R. (1995). Nature 377, 737740.

Morrison, B. W., and Leder, P. (1994). Oncogene 9, 3417-3426.

Morrison, B. W., Moorman, J. R., Kowdley, G. C., Kobayashi, Y. M., Jones, L. R., and Leder, P. (1995). J. Biol. Chem. 270, 21762182.
Palmer, C. J., Scott, B. T., and Jones, L. R. (1991). J. Biol. Chem. 266 $11126-11130$

$\mathrm{Pu}$, H. X., Cluzeaud, F., Goldshlegger, R., Karlish, S. J. D., Farman, N., and Blostein, R. (2001). J. Biol. Chem. 276, 20370-20378.

Shi, H., Levy-Holzman, R., Cluzeaud, F., Farman, N., and Garty, H. (2001). Am. J. Physiol. 280, F505-F512.

Sweadner, K. J., and Rael, E. (2000). Genomics 68, 41-56.

Yamaguchi, F., Yamaguchi, K., Tai, Y., Sugimoto, K., and Tokuda, M. (2001). Brain Res. Mol. Brain Res. 86, 189-192.

Zhang, X.-Q., Qureshi, A., Song, J., Carl, L. L., Tian, Q., Stahl, R. C., Carey, D. J., Rothblum, L. I., and Cheung, J. Y. (2003). Am. J. Physiol. 284, H225-H233. 